\title{
Observation of Optical Properties of Neodymium Oxide with Spectroscopic Ellipsometry
}

\author{
XIAOJIAO FAN, ${ }^{1,2}$ HONGXIA LIU,${ }^{1}$ CHENXI FEI, ${ }^{1}$ BO ZHONG, ${ }^{1}$ \\ XING WANG, ${ }^{1}$ and QIANQIONG WANG $^{1}$
}

1.-School of Microelectronics, Key Laboratory of Wide Band-Gap Semiconductor Materials and Devices, Xidian University, Xi'an 710071, China. 2.-e-mail: fanxiaojiao@stu.xiduan.edu.cn

\begin{abstract}
The annealing dependence of the optical properties of $\mathrm{Nd}_{2} \mathrm{O}_{3}$ films deposited by atomic layer deposition has been investigated by variable-angle spectroscopic ellipsometry (VASE). Based on VASE measurements, it is found that the refractive index and high-frequency dielectric constant decrease with increasing annealing temperature. The optical bandgap energy extracted using the Cody method varies from $4.13 \mathrm{eV}$ for the as-grown state to $4.78 \mathrm{eV}$ for the film annealed at $900^{\circ} \mathrm{C}$. Moreover, three proposed physical models with corresponding optical models are applied to fit the experimental data to understand the possible structural change of the films with annealing temperature. Fitting results indicate that the interfacial interaction between the substrate and the film bulk occurs during the postdeposition annealing procedure and the surface properties of the $\mathrm{Nd}_{2} \mathrm{O}_{3}$ films are improved after annealing at $900^{\circ} \mathrm{C}$. It is shown that the extracted VASE parameters well represented the characteristics of $\mathrm{Nd}_{2} \mathrm{O}_{3} / \mathrm{SiO}_{2} / \mathrm{Si}$ stacks with different annealing temperatures.
\end{abstract}

Key words: High- $k, \mathrm{Nd}_{2} \mathrm{O}_{3}$, atomic layer deposition, spectroscopic ellipsometry

\section{INTRODUCTION}

The downscaling of metal-oxide-semiconductor field-effect transistors (MOSFETs) requires the development of high- $k$ dielectrics, as silicon-dioxidebased gate dielectrics approach their fundamental physical limits. Recently, the rare-earth sesquioxide $\mathrm{Nd}_{2} \mathrm{O}_{3}$, as one of the promising candidates, has become attractive because of its high dielectric constant $(k=10$ to 15$),{ }^{1-4}$ wide bandgap $\left(E_{\mathrm{g}} \approx\right.$ $5.8 \mathrm{eV}),{ }^{5,6}$ and good lattice matching and thermodynamic stability in contact with silicon substrate. ${ }^{6}$ It also has good insulating properties and an appropriate band offset (over $1 \mathrm{eV}$ ) with $\mathrm{Si}$ for microelectronic applications. ${ }^{6-8}$

Variable-angle spectroscopic ellipsometry (VASE) is an efficient, noncontact tool to probe the optical properties of a sample. ${ }^{9-13}$ It allows the determination

(Received August 3, 2014; accepted January 27, 2015; published online February 24, 2015) of a material's optical functions, refractive index $n$, extinction coefficient $k$, and thickness for multilayer films in a nondestructive manner. In the semiconductor industry, VASE has been used to characterize a variety of different materials such as $\mathrm{HfO}_{2},{ }^{14,15} \mathrm{ZrO}_{2},{ }_{17}, 16 \mathrm{Ta}_{2} \mathrm{O}_{5},{ }^{9}$ and indium tin oxide (ITO) thin films. ${ }^{17}$

Although several studies have focused on the electrical and compositional properties of $\mathrm{Nd}_{2} \mathrm{O}_{3}$ films deposited by atomic layer deposition (ALD), ${ }^{1,4,8}$ the optical properties of $\mathrm{Nd}_{2} \mathrm{O}_{3} / \mathrm{SiO}_{2} / \mathrm{Si}$ stacks have not been investigated systematically. In this work, VASE was used to investigate the dependence of the optical properties of the dielectric films on the postdeposition annealing temperature. The variations of refractive index, extinction coefficient, and high-frequency dielectric constant with annealing temperature are presented. Bandgap energies of all the samples are extracted. Besides, the behavior of $\mathrm{Nd}_{2} \mathrm{O}_{3}$ on annealing is investigated using proposed single-, double-, and triple-layer physical models. 


\section{EXPERIMENTAL PROCEDURES}

Film depositions were performed in a commercial R-SERIES-150 ALD reactor. $\mathrm{Nd}_{2} \mathrm{O}_{3}$ films were grown on $p$-type silicon (100) substrates with resistivity of $8 \Omega \mathrm{cm}$ to $12 \Omega \mathrm{cm}$. Before the deposition, the wafers were cleaned with a standard Radio Corporation of America (RCA) method. ${ }^{18}$ Native oxide on silicon was not removed before deposition. Volatile $\mathrm{Nd}(\text { thd })_{3} \quad$ (thd $=2,2,6,6$-tetramethyl-3,5heptanedionato) and ozone were used as precursors. Nitrogen was used as carrier and purge gas. The $\mathrm{Nd}_{2} \mathrm{O}_{3}$ films were deposited at reduced pressure of $10 \mathrm{mbar}$ to $12 \mathrm{mbar}$ at temperature of $320^{\circ} \mathrm{C}$. Five hundred growth cycles were carried out with fixed precursor pulse length of $1 \mathrm{~s}$ and $1.5 \mathrm{~s}$ for $\mathrm{Nd}(\text { thd })_{3}$ and $\mathrm{O}_{3}$, respectively. Selected $\mathrm{Nd}_{2} \mathrm{O}_{3}$ samples were annealed at $700^{\circ} \mathrm{C}$ and $900^{\circ} \mathrm{C}$ for $5 \mathrm{~min}$ in $\mathrm{N}_{2}$ ambient atmosphere. All measurements were performed with a J.A. Woollam VASE ellipsometer at room temperature. Selected as-grown and annealed samples with nominal thickness of $18 \mathrm{~nm}$ were characterized at wavelength from $190 \mathrm{~nm}$ to $1200 \mathrm{~nm}$. To improve accuracy and provide crosscheck modeling, optical data were obtained at light incident angles of $55^{\circ}, 65^{\circ}$, and $75^{\circ}$.

\section{RESULTS AND DISCUSSION}

\section{Determination of Refractive Index $(n)$ and Extinction Coefficient $(k)$}

To determine the refractive index $(n)$ and extinction coefficient $(k)$, the film thickness should be determined first. For all selected samples, a threelayer model ( $\mathrm{Si}$ substrate/native $\mathrm{SiO}_{2}$ layer/ $/ \mathrm{Nd}_{2} \mathrm{O}_{3}$ layer) was used to extract corresponding optical parameters. The obtained VASE data were modeled using optical models for $\mathrm{SiO}_{2}$ and $\mathrm{Si}$ layers provided by J.A. Woollam, Inc., and a Cauchy model was applied for the $\mathrm{Nd}_{2} \mathrm{O}_{3}$ layer in a nonabsorbing region of $1 \mathrm{eV}$ to $3 \mathrm{eV}$ in this case. The thickness of the $\mathrm{Nd}_{2} \mathrm{O}_{3}$ layer was variable, while the optical properties of the layer and thickness of the underlying $\mathrm{Si}$ and $\mathrm{SiO}_{2}$ were constant. The fixed thicknesses of the underlying $\mathrm{Si}$ substrate and $\mathrm{SiO}_{2}$ layers were determined from measurements of the $\mathrm{Si} / \mathrm{SiO}_{2}$ stacks before deposition. The obtained thicknesses were $17.347 \mathrm{~nm}, 17.980 \mathrm{~nm}$, and $15.623 \mathrm{~nm}$ for the as-grown sample and samples annealed at $700^{\circ} \mathrm{C}$ and $900^{\circ} \mathrm{C}$, respectively, with mean square error (MSE) ${ }^{19}$ of less than $2.163 \mathrm{~nm}$ as presented in Table I.
With the fixed film thickness, the refractive index $(n)$ and extinction coefficient $(k)$ were obtained by applying a pointwise fitting procedure over the entire spectral range, as shown in Fig. 1.

The refractive index was 1.862 at wavelength of $620 \mathrm{~nm}(2 \mathrm{eV})$ for the as-grown sample. This value is slightly lower than the value of 2.1 reported in literature. ${ }^{20}$ In particular, it was observed that the refractive index followed a normal dispersion behavior with photon energy, increasing as the photon energy increased. Furthermore, a decrease in film refractive index was obvious with increasing annealing temperature. A similar trend has been observed for $\mathrm{Er}_{2} \mathrm{O}_{3} / \mathrm{Si}^{21,22}$ and $\mathrm{HfO}_{2} / \mathrm{Si}^{23}$ annealed in $\mathrm{N}_{2}$ ambient. However, the opposite trend was reported for $\mathrm{Y}_{2} \mathrm{O}_{3} / \mathrm{Si}$ and $\mathrm{ZrO}_{2} / \mathrm{Si}^{24}$ annealed in air ambient, and $\mathrm{HfO}_{2} / \mathrm{Si}^{25}$ annealed in oxygen ambient. In particular, the film annealed at $900^{\circ} \mathrm{C}$ exhibited the lowest refractive index, being attributed to a decrease in the packing density with higher crystallinity and incorporation of silicon into the film with increasing annealing temperature. It is known that $\mathrm{Si}$ atoms can easily diffuse from the substrate into the films to form $\mathrm{Nd}$ silicate or more silicon oxide components at the interfacial layer with increasing annealing temperature. ${ }^{26}$ Film density is expected to decrease due to the contribution of the lower film density of $2.37 \mathrm{~g} / \mathrm{cm}^{3}$ for $\mathrm{SiO}_{2}$. Moreover, the film morphology may evolve from an amorphous configuration to polycrystalline at lower annealing temperature $\left(700^{\circ} \mathrm{C}\right)$, and eventually to a more crystalline configuration at higher annealing temperature $\left(900^{\circ} \mathrm{C}\right) .^{27}$ Due to the lower packing density with higher crystallinity, ${ }^{28,29}$ the decrease in refractive index is expected. This trend was also observed for $\mathrm{Er}_{2} \mathrm{O}_{3}{ }^{21}$ films after high-temperature heat treatment.

Figure 1 also shows the extinction coefficient data for the three samples. It was observed that the transparent regime $(k=0)$ is evident at lower energies. On the other hand, an extinction onset at $5.34 \mathrm{eV}$ corresponding to absorption across the bandgap of the film was found for the sample annealed at $900^{\circ} \mathrm{C}$. However, the data recorded from the as-grown film and the film annealed at $700^{\circ} \mathrm{C}$ showed a pronounced feature at lower energy, with a shoulder at $4.7 \mathrm{eV}$ followed by a rapid rise above $5.0 \mathrm{eV}$. This rapid rise is associated with absorption due to optical transitions through the bandgap, while the former features are attributed to interfacial defect states below the band edge. ${ }^{30-32}$ The

Table I. Dispersion parameters of $\mathrm{Nd}_{2} \mathrm{O}_{3}$ films with different annealing temperatures

\begin{tabular}{|c|c|c|c|c|c|c|}
\hline Sample & Thickness (nm) & $S_{0}\left(\mathrm{~m}^{-2}\right)$ & $\lambda_{0}(\mathrm{~nm})$ & $\varepsilon_{\infty}$ & $E_{0}(\mathrm{eV})$ & $E_{0} / S_{0}$ \\
\hline As grown & 17.347 & $0.106 \times 10^{15}$ & 147 & 3.29 & 8.434 & $7.939 \times 10^{-14}$ \\
\hline $700^{\circ} \mathrm{C}$ & 17.980 & $0.108 \times 10^{15}$ & 146 & 3.30 & 8.492 & $7.852 \times 10^{-14}$ \\
\hline $900^{\circ} \mathrm{C}$ & 15.623 & $0.113 \times 10^{15}$ & 140 & 3.23 & 8.856 & $7.806 \times 10^{-14}$ \\
\hline
\end{tabular}




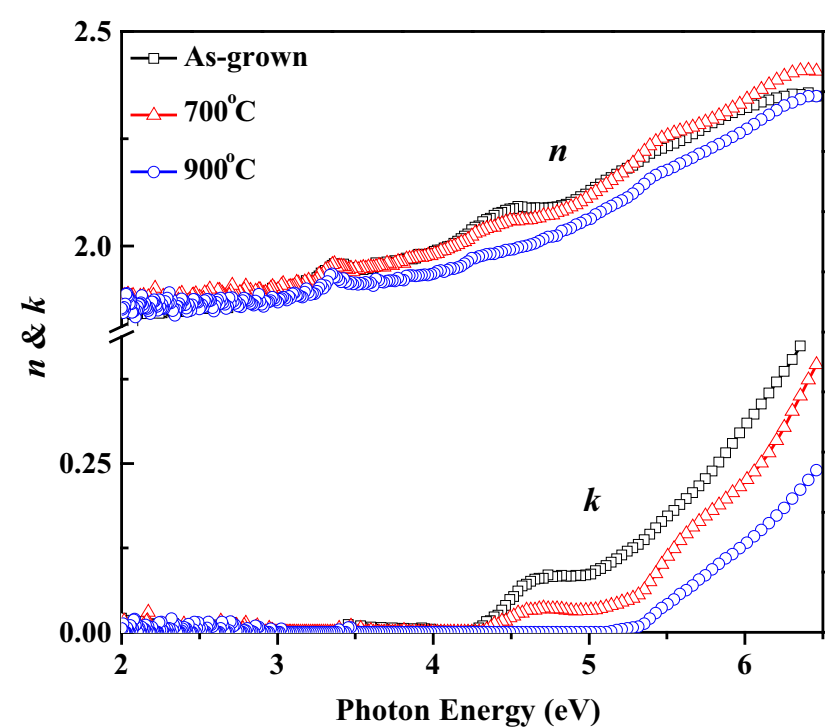

Fig. 1. Refractive index $(n)$ and extinction coefficient $(k)$ for all selected samples.

absence of subband defect states in the sample annealed at $900^{\circ} \mathrm{C}$ indicates that the high temperature greatly reduced film defects. These trends are in agreement with the trends reported for $\mathrm{HfO}_{2}$ deposited by ALD. ${ }^{30,33}$

\section{Refractive Index Dispersion Analysis}

The resultant data on the refractive index can be analyzed to obtain the high-frequency dielectric constant $\left(\varepsilon_{\infty}\right)$, average oscillator wavelength $\left(\lambda_{0}\right)$, and oscillator strength $\left(S_{0}\right)$ for the films by applying the following simple classical dispersion relation: ${ }^{34-37}$

$$
\begin{gathered}
n^{2}-1=\frac{S_{0} \lambda_{0}^{2}}{1-\lambda_{0}^{2} / \lambda^{2}}, \\
S_{0}=\frac{\left(n_{0}^{2}-1\right)}{\lambda_{0}^{2}},
\end{gathered}
$$

where $\lambda_{0}$ is the average oscillator position, $S_{0}$ is the average oscillator strength, and $n_{0}$ is the refractive index at infinite wavelength $\lambda_{0}$ (the average interband oscillator wavelength). The plots of $1 /\left(n^{2}-1\right)$ versus $1 / \lambda^{2}$ give straight lines with different slopes, and can be fit well by the classical single electronic oscillator dispersion formula, as shown in Fig. 2. The parameters $S_{0}$ and $\lambda_{0}$ can be deduced from the slope $\left(-1 / S_{0}\right)$ of the resulting straight line and the infinite-wavelength intercept $\left(1 / S_{0} \lambda_{0}^{2}\right)$, respectively. The refractive index dispersion parameter $\left(E / S_{0}\right)$ and the high-frequency dielectric constant $\left(\varepsilon_{\infty}=n_{0}^{2}\right)$, which depend on the characteristics of the various interband transitions, can also be determined, as presented in Table I.

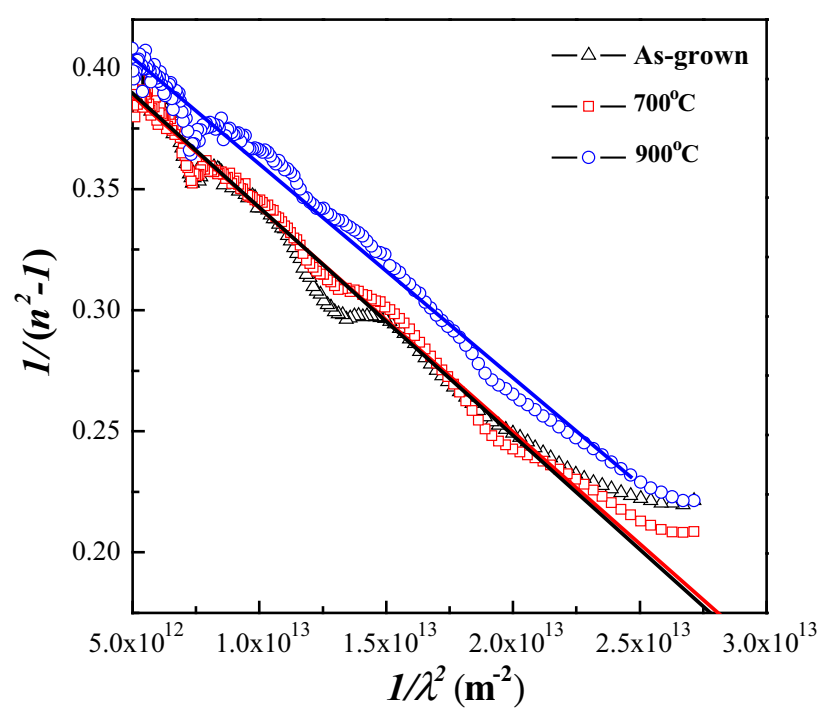

Fig. 2. Plots of $1 /\left(n^{2}-1\right)$ versus $1 / \lambda^{2}$ for $\mathrm{Nd}_{2} \mathrm{O}_{3}$ films treated at different annealing temperatures.

From Table I, it can be noted that the highfrequency dielectric constant decreases with increasing annealing temperature, originating from the decrease in the refractive index of the films. The average interband oscillator energy can be given by $E_{0}=h c / \lambda_{0}$, where $h$ is Planck's constant and $c$ is the velocity of light. The estimated $E_{0}$ values increase with the annealing temperature. Furthermore, the evaluated $E_{0} / S_{0}$ values are of the same order as those obtained for $\mathrm{HfO}_{x} \mathrm{~N}_{y}$ films. ${ }^{35}$

\section{Optical Bandgap Determination}

To determine the bandgap values of the as-grown and annealed $\mathrm{Nd}_{2} \mathrm{O}_{3}$ films, Cody plots ${ }^{38}$ of $(\alpha n / E)^{1 / 2}$ versus photon energy $E$ were employed, where the absorption coefficient $\alpha$ is defined as $\alpha=4 \pi k / \lambda, \lambda$ is the light wavelength, and $k$ is the extinction coefficient.

From Fig. 3, the bandgap of the as-grown film is measured to be about $4.13 \mathrm{eV}$. After annealing at $700^{\circ} \mathrm{C}$ and $900^{\circ} \mathrm{C}$, the bandgap $E_{\text {g }}$ increases from $4.6 \mathrm{eV}$ to $4.78 \mathrm{eV}$. The bandgap energy obtained for the as-grown sample is smaller than the reported value of $5.8 \mathrm{eV}$ found from the $\mathrm{O}$ 1s energy loss spectrum. ${ }^{5}$ The variation appears to relate to the methods of deposition, film thickness, and experimental techniques used to obtain the bandgap energy. Furthermore, bandgap increase is observed with annealing temperature growth. It is believed that the presence of defects and disorder in the film would produce localized states in the band structure and contribute to the low value of the energy gap. Meanwhile, the annihilation of oxygen vacancies and disorder in the annealed film would result in decreased density of localized states in the band and increase of the bandgap. ${ }^{35,39}$ Additionally, crystalline oxides may have larger bandgap. ${ }^{40}$ Similar 


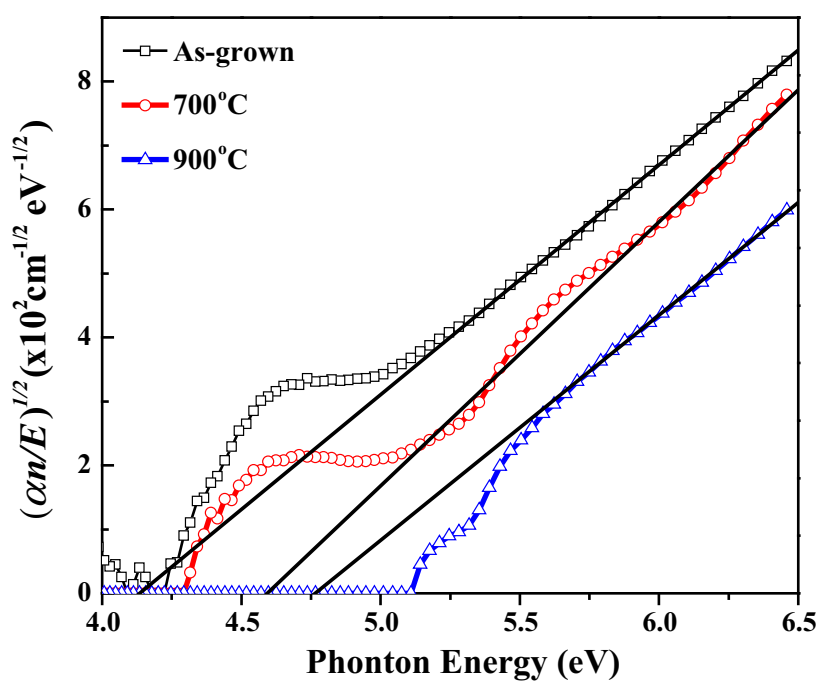

Fig. 3. Curves of $(\alpha n / E)^{1 / 2}$ versus photon energy $E$.

results were reported for $\mathrm{Hf}$ silicate $^{41}$ and Er oxide ${ }^{21}$ on silicon substrates.

\section{Physical Models}

To understand the effects of annealing on the physical and optical properties of the $\mathrm{Nd}_{2} \mathrm{O}_{3} / \mathrm{SiO}_{2} / \mathrm{Si}$ gate stacks, three physical models were considered to describe the $\mathrm{Nd}_{2} \mathrm{O}_{3}$ films. First, a single homogeneous layer model (M1) was assumed, as shown in Fig. 4a, and a Cody-Lorentz (C-L) oscillator model ${ }^{19}$ was applied to describe the $\mathrm{Nd}_{2} \mathrm{O}_{3}$ layer. The second proposed model (M2) consisted of a double-layer film with dense $\mathrm{Nd}_{2} \mathrm{O}_{3}$ layer and surface roughness layer (SRL), as shown in Fig. 4b. The $\mathrm{C}-\mathrm{L}$ model and srough model [a shorthand for the $50 \%$ effective medium approximation (EMA) mixture of $\mathrm{Nd}_{2} \mathrm{O}_{3}$ and void optical constants] were used for simultaneous fitting in this case. Considering the possible interaction at the interface between the $\mathrm{Nd}_{2} \mathrm{O}_{3}$ and $\mathrm{SiO}_{2}$ layer, the third proposal (M3) included a heterogeneous mixture layer of $\mathrm{Nd}_{2} \mathrm{O}_{3}$ and $\mathrm{SiO}_{2}$ material (Fig. 4c). The mixture was modeled using the Bruggeman effective medium approximation (BEMA) for the estimation of the component fraction.

The three proposed physical models were fit against the experimental data curves. The results obtained using the models for the as-grown films and those annealed at $700^{\circ} \mathrm{C}$ and $900^{\circ} \mathrm{C}$ are presented in Tables II, III, and IV, respectively.

The MSE can be used to quantify the quality of the match between the experimental and modeled data. The smaller the MSE value, the more accurate the film structure prediction. It can be seen from Table II that the MSE values decrease as more complicated physical models are applied, indicating that M3 may provide the most probable physical structure of the as-grown film. Similar variation trends are also observed for the annealed samples in Tables III and IV. Comparison of the MSE values

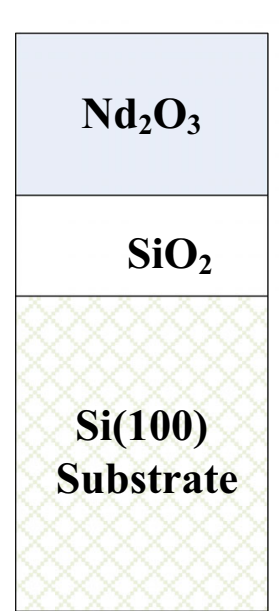

(a)

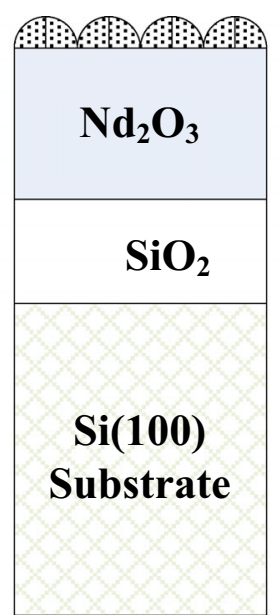

(b)

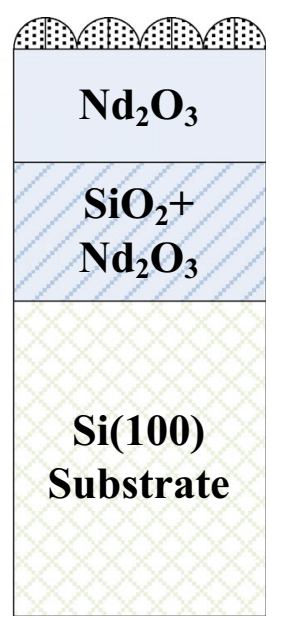

(c)
Fig. 4. Schematic representation of the proposed (a) single- (M1), (b) double- (M2), and (c) triple-layer models (M3) for the SE modeling procedure.

suggests that M3 may provide the most probable physical structure for all three samples.

Furthermore, it is noticed that the fractional content of $\mathrm{Nd}_{2} \mathrm{O}_{3}$ in the BEMA layer was -0.34 for the as-grown sample, except when applying model M3. This result further validates the hypothesis that interfacial interaction between $\mathrm{Nd}_{2} \mathrm{O}_{3}$ and $\mathrm{SiO}_{2}$ barely occurs during the film deposition. However, a fractional content of $\mathrm{Nd}_{2} \mathrm{O}_{3}$ of 0.048 was found for the sample annealed at $700^{\circ} \mathrm{C}$, suggesting interfacial reaction between $\mathrm{SiO}_{2}$ and $\mathrm{Nd}_{2} \mathrm{O}_{3}$. Further increase of the annealing temperature to $900^{\circ} \mathrm{C}$ resulted in a lower value of the fractional content of $\mathrm{Nd}_{2} \mathrm{O}_{3}$ of 0.026 . The decreased $\mathrm{Nd}_{2} \mathrm{O}_{3}$ fraction indicates less $\mathrm{Nd}$ oxide component in the interfacial layer between the silicon substrate and the bulk $\mathrm{Nd}_{2} \mathrm{O}_{3}$ layer. This trend can be understood because more silicon atoms may diffuse from the substrate into the films with increasing annealing temperature, and $\mathrm{Nd}$ silicate component with higher silicon oxide component at the interfacial layer may be formed when annealing at $900^{\circ} \mathrm{C} .^{8,26}$

The analysis of the MSE and the fractional content of $\mathrm{Nd}_{2} \mathrm{O}_{3}$ in the BEMA layer indicates that the most suitable physical model for the as-grown sample is M2. For the annealed samples, model M3 provides the most accurate description of the film structure.

Moreover, the thickness of the surface roughness layer is presented in Tables I, III, and IV. The fitting results in the framework of model M2 are used to obtain the variation of the thickness of the SRL depending on the annealing temperature. It can be seen that the SRL thickness decreased from $0.437 \mathrm{~nm}$ to $0.425 \mathrm{~nm}$ after annealing at $700^{\circ} \mathrm{C}$ and to $0.119 \mathrm{~nm}$ after annealing at $900^{\circ} \mathrm{C}$. It is evident that higher-temperature annealing at $900^{\circ} \mathrm{C}$ significantly improved the film surface properties. 
Table II. Results from VASE analysis of $\mathrm{Nd}_{2} \mathrm{O}_{3}$ films (as grown)

\begin{tabular}{|c|c|c|c|c|c|}
\hline Physical Model & Sublayers & Fitting Model & Thickness (nm) & MSE & $\mathrm{Nd}_{2} \mathrm{O}_{3}$ Fraction \\
\hline M1 & $\mathrm{Nd}_{2} \mathrm{O}_{3}$ & $\mathrm{C}-\mathrm{L}$ & 17.523 & 3.137 & - \\
\hline \multirow[t]{2}{*}{ M2 } & SRL & Srough & 0.437 & 3.106 & - \\
\hline & $\mathrm{Nd}_{2} \mathrm{O}_{3}$ & $\mathrm{C}-\mathrm{L}$ & 17.421 & & \\
\hline \multirow[t]{3}{*}{ M3 } & SRL & Srough & 0.811 & 2.902 & -0.34 \\
\hline & $\mathrm{Nd}_{2} \mathrm{O}_{3}$ & $\mathrm{C}-\mathrm{L}$ & 16.802 & & \\
\hline & $\mathrm{SiO}_{2}+\mathrm{Nd}_{2} \mathrm{O}_{3}$ & BEMA & 1.895 & & \\
\hline
\end{tabular}

Table III. Results from VASE analysis of $\mathrm{Nd}_{2} \mathrm{O}_{3}$ films (annealed at $700^{\circ} \mathrm{C}$ )

\begin{tabular}{|c|c|c|c|c|c|}
\hline Physical Model & Sublayers & Fitting Model & Thickness (nm) & MSE & $\mathrm{Nd}_{2} \mathrm{O}_{3}$ Fraction \\
\hline M1 & $\mathrm{Nd}_{2} \mathrm{O}_{3}$ & $\mathrm{C}-\mathrm{L}$ & 18.012 & 2.704 & - \\
\hline \multirow[t]{2}{*}{ M2 } & Srough & Srough & 0.425 & 2.685 & - \\
\hline & $\mathrm{Nd}_{2} \mathrm{O}_{3}$ & $\mathrm{C}-\mathrm{L}$ & 17.878 & & \\
\hline \multirow[t]{3}{*}{ M3 } & Srough & Srough & 0.418 & 2.653 & 0.048 \\
\hline & $\mathrm{Nd}_{2} \mathrm{O}_{3}$ & $\mathrm{C}-\mathrm{L}$ & 17.516 & & \\
\hline & $\mathrm{SiO}_{2}+\mathrm{Nd}_{2} \mathrm{O}_{3}$ & BEMA & 1.597 & & \\
\hline
\end{tabular}

Table IV. Results from VASE analysis of $\mathrm{Nd}_{2} \mathrm{O}_{3}$ films (annealed at $900^{\circ} \mathrm{C}$ )

\begin{tabular}{|c|c|c|c|c|c|}
\hline Physical Model & Sublayers & Fitting Model & Thickness (nm) & MSE & $\mathrm{Nd}_{2} \mathrm{O}_{3}$ Fraction \\
\hline M1 & $\mathrm{Nd}_{2} \mathrm{O}_{3}$ & $\mathrm{C}-\mathrm{L}$ & 15.658 & 4.718 & - \\
\hline \multirow[t]{2}{*}{ M2 } & Srough & Srough & 0.119 & 4.688 & - \\
\hline & $\mathrm{Nd}_{2} \mathrm{O}_{3}$ & $\mathrm{C}-\mathrm{L}$ & 15.556 & & \\
\hline \multirow[t]{3}{*}{ M3 } & Srough & Srough & 0.095 & 4.653 & 0.026 \\
\hline & $\mathrm{Nd}_{2} \mathrm{O}_{3}$ & $\mathrm{C}-\mathrm{L}$ & 15.452 & & \\
\hline & $\mathrm{SiO}_{2}+\mathrm{Nd}_{2} \mathrm{O}_{3}$ & BEMA & 1.633 & & \\
\hline
\end{tabular}

Similar results have been obtained by other groups $^{3,42}$ using atomic force microscopy (AFM).

\section{CONCLUSIONS}

VASE was used to evaluate the optical properties of high- $k$ dielectric $\mathrm{Nd}_{2} \mathrm{O}_{3} / \mathrm{SiO}_{2} / \mathrm{Si}$ stacks as a function of annealing temperature. It was found that the refractive index $(n)$ decreases with increasing annealing temperature due to the decrease in packing density with higher crystallinity and silicon incorporation into the film. Analysis of extinction coefficient data showed that subband states, related to defects in the film, were significantly reduced after annealing at $900^{\circ} \mathrm{C}$. Moreover, the highfrequency dielectric constant decreased with increase in annealing temperature, originating from the decrease in the refractive index of the film. The optical bandgap extracted using the Cody method varied from $4.13 \mathrm{eV}$ for the as-grown film to $4.78 \mathrm{eV}$ for the film annealed at $900^{\circ} \mathrm{C}$. Besides, the behavior of $\mathrm{Nd}_{2} \mathrm{O}_{3}$ was investigated using different reflection models. Analysis of the MSE and the fractional content of $\mathrm{Nd}_{2} \mathrm{O}_{3}$ in the BEMA layer indicated that the M2 physical model is the most suitable for the as-grown sample. For the annealed samples, while M2 provides reasonable fitting results, M3 may provide the most accurate description of the film structure. Furthermore, the thickness of the SRL decreases with increase of the annealing temperature, suggesting that annealing at a higher temperature of $900^{\circ} \mathrm{C}$ significantly improves the surface properties of the film. Thus, the VASE technique has been proven to be an efficient way to characterize the samples without film destruction.

\section{ACKNOWLEDGEMENTS}

This work was supported in part by the Project of the National Natural Science Foundation of China (Grant Nos. 61376099, 11235008) and in part by the Specialized Research Fund for the Doctoral Program of High Education (Grant No. 20110203110012).

\section{REFERENCES}

1. J. Päiväsaari, M. Putkonen, and L. Niinistö, Thin Solid Films 472, 275 (2005). 
2. S. Jeon, K. Im, H. Yang, H. Lee, H. Sim, S. Choi, T. Jang, and H. Hwang, Technical Digest International Electron Devices Meeting (IEDM'01), Dec 2-5 (Washington, DC, USA, 2010), p. 20.6.1.

3. M.K. Song and S.W. Rhee, Thin Solid Films 492, 19 (2005).

4. A. Kosola, J. Päiväsaari, M. Putkonen, and L. Niinistö, Thin Solid Films 479, 152 (2005).

5. A. Laha, A. Fissel, E. Bugiel, and H.J. Osten, Thin Solid Films 515, 6512 (2007).

6. A. Fissel, Z. Elassar, O. Kirfel, E. Bugiel, M. Czernohorsky, and H.J. Osten, J. Appl. Phys. 99, 074105 (2006).

7. T.-M. Pan, J.-D. Lee, and W.-W. Yeh, J. Appl. Phys. 101, 024110 (2007).

8. X. Fan, H. Liu, and C. Fei, Mater. Res. Express 1, 045005 (2014).

9. D.-X. Zhang, Y.-X. Zheng, Q.-Y. Cai, W. Lin, W. Kang-Ning, P.-H. Mao, R.-J. Zhang, H.-B. Zhao, and L.-Y. Chen, Appl. Phys. A 108, 975 (2012)

10. M. Losurdo, M. Bergmair, G. Bruno, D. Cattelan, C. Cobet, A. de Martino, K. Fleischer, Z. Dohcevic-Mitrovic, N. Esser, M. Galliet, R. Gajic, D. Hemzal, K. Hingerl, J. Humlicek, R. Ossikovski, Z.V. Popovic, and O. Saxl, J. Nanopart. Res. 11, 1521 (2009).

11. V.V. Atuchin, A.V. Kalinkin, V.A. Kochubey, V.N. Kruchinin, R.S. Vemuri, and C.V. Ramana, J. Vac. Sci. Technol. A 29, 021004 (2011).

12. Y.H. Wong, V.V. Atuchin, V.N. Kruchinin, and K.Y. Cheong, Appl. Phys. A 115, 1069 (2013).

13. E.J. Rubio, V.V. Atuchin, V.N. Kruchinin, L.D. Pokrovsky, I.P. Prosvirin, and C.V. Ramana, J. Phys. Chem. C 118, 13644 (2014).

14. B. Ayupov, K. Zherikova, N. Gelfond, and N. Morozova, Phys. Status Solidi A 206, 281 (2009).

15. J. Price, P. S. Lysaght, S. C. Song, A. C. Diebold, Y. Q. An, and M. C. Downer, Phys. Status Solidi A 205, 918 (2008).

16. J. Sellmann, C. Sturm, R. Schmidt-Grund, C. Czekalla, J. Lenzner, H. Hochmuth, B. Rheinländer, M. Lorenz, and M. Grundmann, Phys. Status Solidi C 5, 1240 (2008).

17. L. KÖrösi, S. Papp, S. Beke, B. Pécz, R. Horváth, P. Petrik, E. Agócs, and I. Dékány, Appl. Phys. A 107, 385 (2012).

18. W. Kern and D. Puotinen, RCA Rev. 31, 187 (1970).

19. H. Mati, P. Chindaudom, and P. Limsuwan, Chin. Phys. Lett. 24, 1505 (2007).

20. O. Medenbach, D. Dettmar, R.D. Shannon, R.X. Fischer, and W.M. Yen, J. Opt. A 3, 174 (2001).

21. H.S. Kamineni, V.K. Kamineni, R.L. Moore, S. Gallis, A.C. Diebold, M. Huang, and A.E. Kaloyeros, J. Appl. Phys. 111, 013104 (2012).
22. M. Losurdo, M.M. Giangregorio, G. Bruno, D. Yang, E.A. Irene, A.A. Suvorova, and M. Saunders, Appl. Phys. Lett. 91, 091914 (2007).

23. P. Boher, C. Defranoux, P. Heinrich, J. Wolstenholme, and H. Bender, Mater. Sci. Eng. B 109, 64 (2004).

24. J.J. Yoon, S.M. Lee, T.J. Kim, S.Y. Hwang, M. Diware, Y.D. Kim, S.M. Hwang, and J. Joo, J. Vac. Sci. Technol. B 29, 04D108 (2011).

25. B. Deng, G. He, X.S. Chen, X.F. Chen, J.W. Zhang, M. Liu, J.G. Lv, and Z.Q. Sun, J. Mater. Sci. 25, 4163 (2014).

26. H. Ono and T. Katsumata, Appl. Phys. Lett. 78, 1832 (2001).

27. C.H. Kao, H. Chen, Y.-C. Liao, J.Z. Deng, Y.C. Chu, Y.T. Chen, and H.W. Chang, Thin Solid Films 570, 412 (2014).

28. F.L. Martínez, M. Toledano-Luque, J.J. Gandía, J. Cárabe, W. Bohne, J. Röhrich, E. Strub, and I. Mártil, J. Phys. D 40, 5256 (2007).

29. I.Z. Mitrovic, O. Buiu, S. Hall, C. Bungey, T. Wagner, W. Davey, and Y. Lu, Microelectron. Reliab. 47, 645 (2007).

30. J. Price, P.S. Lysaght, S.C. Song, H.-J. Li, and A.C. Diebold, Appl. Phys. Lett. 91, 061925 (2007).

31. D.H. Hill, R.A. Bartynski, N.V. Nguyen, A.C. Davydov, D. Chandler-Horowitz, and M.M. Frank, J. Appl. Phys. 103, $093712(2008)$

32. N.V. Nguyen, A.V. Davydov, D. Chandler-Horowitz, and M.M. Frank, Appl. Phys. Lett. 87, 192903 (2005).

33. Y.J. Cho, N.V. Nguyen, C.A. Richter, J.R. Ehrstein, B.H. Lee, and J.C. Lee, Appl. Phys. Lett. 80, 1249 (2002).

34. F. Yakuphanoglu, A. Cukurovali, and I. Yilmaz, Phys. B 351, 53 (2004)

35. G. He, L.D. Zhang, M. Liu, J.P. Zhang, X.J. Wang, and C.M. Zhen, J. Appl. Phys. 105, 014109 (2009).

36. S.H. Wemple and M. DiDomenico Jr, Phys. Rev. Lett. 23, 1156 (1969).

37. S.H. Wemple and M. DiDomenico Jr, Phys. Rev. B 3, 1338 (1971)

38. M. Diev, E. Bersch, A.C. Diebold, S. Consiglio, R.D. Clark, G.J. Leusink, and T. Kaack, J. Vac. Sci. Technol. A 29, 041001 (2011)

39. M. Liu, Q. Fang, G. He, L. Li, L.Q. Zhu, G.H. Li, and L.D. Zhang, Appl. Phys. Lett. 88, 192904 (2006).

40. S. Sayan, N.V. Nguyen, J. Ehrstein, T. Emge, E. Garfunkel, M. Croft, X. Zhao, D. Vanderbilt, I. Levin, E.P. Gusev, H. Kim, and P.J. Mcintyre, Appl. Phys. Lett. 86, 152902 (2005).

41. J. Price, P.Y. Hung, T. Rhoad, B. Foran, and A.C. Diebold, Appl. Phys. Lett. 85, 1701 (2004).

42. C.-H. Kao, H. Chen, J.S. Chiu, K.S. Chen, and Y.T. Pan, Microelectron. Reliab. 50, 709 (2010). 